(2) OPEN ACCESS

\section{Abortion regulation in Europe in the era of COVID-19: a spectrum of policy responses}

\author{
Caroline Moreau (D) , ,2 Mridula Shankar, ${ }^{1}$ Anna Glasier, ${ }^{3}$ \\ Sharon Cameron (D) , ${ }^{4}$ Kristina Gemzell-Danielsson ${ }^{5}$
} Background Unprecedented public health actions
restricting movement and non-COVID related health services are likely to have affected abortion care during the pandemic in Europe. In the absence of a common approach to ensure access to this essential health service, we sought to describe the variability of abortion policies during the outbreak in Europe in order to identify strategies that improve availability and access to abortion in times of public health crises.

Methods We collected information from 46 countries/regions: 31 for which country-experts completed a survey and 15 for which we conducted a desk review. We describe abortion regulations and changes to regulations and practice during the pandemic.

Dr Caroline Moreau, Population Family and Reproductive Health, Johns Hopkins University Bloomberg School of Public Health, Baltimore, MD 21205, USA; cmoreau2@jhu.edu

Received 30 May 2020 Revised 25 August 2020 Accepted 3 September 2020 Published Online First 22 October 2020

Results During COVID-19, abortions were banned in six countries and suspended in one. Surgical abortion was less available due to COVID-19 in 12 countries/regions and services were not available or delayed for women with COVID-19 symptoms in eleven. No country expanded its gestational limit for abortion. Changes during COVID-19, mostly designed to reduce in-person consultations, occurred in 13 countries/regions. Altogether eight countries/regions provided home medical abortion with mifepristone and misoprostol beyond 9 weeks (from 9 weeks +6 days to 11 weeks +6 days) and 13 countries/regions up to 9 weeks (in some instances only misoprostol could be taken at home). Only six countries/regions offered abortion by telemedicine. Conclusions The lack of a unified policy response to COVID-19 restrictions has widened inequities in abortion access in Europe, but some innovations including telemedicine deployed during the outbreak could serve as a catalyst to ensure continuity and equity of abortion care.

employer(s)) 2021. Re-use permitted under CC BY-NC. No commercial re-use. See rights and permissions. Published by BMJ.

To cite: Moreau C, Shankar $M$, Glasier A, et al. BMJ Sex Reprod Health 2021;47:e14.

\section{INTRODUCTION}

Abortion is an essential component of women's sexual and reproductive care. While extremely safe under recommended procedures, ${ }^{1}$ it is responsible

\section{Key messages}

- In response to COVID-19, European countries have taken different approaches to changing abortion regulations and practices ranging from imposing restrictions to alleviating certain requirements.

- New restrictions include delay or denial of abortion care to women having or living with people having COVID-19 symptoms, and decreased availability of surgical abortion.

- A small number of countries have reduced the number of in-person clinical visits, expanded medical abortion availability via telemedicine, and relaxed regulations around mifepristone delivery and administration.

- The absence of a unified approach to sustain abortion services, restrictions and border closures will widen inequities in access to abortion care across Europe.

for substantial maternal morbidity and mortality when women do not have access to safe abortion care. ${ }^{23}$ Abortion is one of the most common procedures for women of reproductive age in Europe, with an annual incidence rate ranging from 6.4/1000 women aged 15-44 years (Switzerland) to $19.2 / 1000$ (Sweden) in countries with complete official statistics. $^{45}$ Over a 1-month period, more than 34000 abortions are estimated to take place in France, England and Wales together. ${ }^{67}$ The need for abortion is likely to have increased in the wake of the COVID-19 pandemic in Europe, given economic uncertainties, rising reports of sexual violence ${ }^{8}$ and limited access to contraception. However, the unprecedented public health action to 'bend 
the curve' of the pandemic is raising concern over women's ability to access this essential service, due to restrictions in movement and limited availability of non-COVID-related health services, including elective interventions. ${ }^{9}$ These concerns are heightened in the context of abortion, where politics often trumps evidence. With each passing week of political inaction, thousands of women are denied treatment that cannot be postponed, ${ }^{10}$ and face the prospect of carrying an unwanted pregnancy to term or of undergoing unsafe procedures.

Access to abortion care during COVID-19 in Europe is likely to be predicated on existing regulations and government or provider-led responses to women's specific needs during the pandemic. While abortion is widely available for non-medical indications in Europe (with notable exceptions including Poland, Malta, Andorra, Faroe Islands, Liechtenstein, Monaco, San Marino and Northern Ireland (the latter up until 9 April 2020)), the regulations governing access and procedures are extensive and vary substantially from country to country. These regulations fall into two broad categories, as they pertain to the 'demand for' or 'supply of' abortion. On the demand side, measures include mandatory counselling and waiting periods, parental consent, funding regulations or bureaucratic requirements (eg, authorisation by several doctors). On the supply side, restrictions apply to the type of provider who can perform abortions, the type of medical interactions (in-person consultations vs remote consultations), the modalities of medication dispensation or the types of additional examination or procedures required (for gestational dating, anti-D immunoglobulin injection for women with Rhesus-negative blood group). Together these regulations form a constellation of conditions, which are unsupported by scientific evidence and place an unnecessary burden on women who seek abortion care. ${ }^{1}$

This burden is amplified in the context of COVID19, given the time-sensitive nature of abortion care (dependent on legal gestational limits and on the efficacy and safety that vary by gestational age $)^{1}$ and the increased risk of exposing abortion patients to COVID-19 acquisition. ${ }^{9}$ In all, governments have taken almost polar opposite approaches to tackling the issue, from suspension of abortion services, considered non-essential, to the lifting of regulations allowing telemedicine and self-managed care solutions. ${ }^{10}$ The absence of a unified response exposes the variability of existing country-level regulatory requirements, potentially reinforcing inequities in access to abortion in Europe. Thus, a careful exploration of abortion policies during the outbreak is warranted to understand barriers to abortion access in the COVID-19 era, and to identify effective strategies to improve sexual and reproductive health (SRH) care in times of public health crises.
METHODS

We solicited information from 47 experts from 39 countries/regions between 21 April and 14 May 2020 to examine how European countries have adapted policies governing abortion care during COVID-19. The aim was to assess pre-COVID-19 regulations as well as policy changes during the pandemic in the European region, as defined by the United Nation's geoscheme (https://unstats.un.org/unsd/methodology/ $\mathrm{m} 49 /$ ) with the addition of Georgia, as we had contact information for this additional country. Experts were healthcare professionals or public health practitioners involved in abortion-related research or clinical care. They were invited to share this information via a 7 -min questionnaire completed electronically or on paper. This study did not require ethical committee approval as it does not qualify as human subjects' research. We collected information from 46 countries/regions overall, including 31 for which 32 country-experts completed our survey and 15 for which we conducted a desk review of abortion policies in the absence of a completed survey.

In this article, we describe abortion regulations across Europe and changes to regulations and/or practice that were implemented during the COVID-19 pandemic. We examine how country responses (official or provider-led) varied according to pre-COVID regulatory conditions and provide a narrative description of expert suggestions to improve abortion services during this global pandemic.

\section{Patient and public involvement statement}

This public policy analysis does not involve patients or the public in the design, or conduct, or reporting, or dissemination plans of this work.

\section{RESULTS}

Increasing barriers to abortion access during COVID-19 In the context of COVID-19, abortion care was available to varying extents in 39 countries/regions, banned for nonmedical reasons in six countries (Andorra, Liechtenstein, Malta, Monaco, San Marino and Poland) and suspended in Hungary due to a ban on non-life-threatening surgeries in state hospitals. In Poland, amid the COVID-19 crisis, the parliament discussed additional restrictions to ban abortion for fetal anomalies in April 2020 but deferred a final decision. In Northern Ireland, guidelines for abortion care were issued in March 2020 but these did not include safe options during the COVID-19 pandemic. Mounting pressure on the Department of Health to address this issue resulted in the provision of medical abortion with home use of misoprostol on 9 April 2020. ${ }^{11}$ Other limitations were noted in 31 countries/regions represented in the survey. Abortion care was not available for women who had COVID-19 symptoms or were living with someone who presented with symptoms in the Netherlands. Ten countries/regions suggested abortion care was to be delayed in symptomatic women or those testing 
positive for coronavirus (Belgium, Germany, Iceland, Latvia, Luxembourg, Montenegro, Slovenia, England, Wales and Scotland). In 13 surveyed countries, experts considered that surgical abortion was likely to be less available due to COVID-19 including Hungary where surgical abortion was suspended.

\section{Lifting of regulatory barriers for medical abortion was rare}

Lack of access to surgical abortion was rarely compensated by the lifting of regulatory barriers for medical abortion. Expansions to medical abortion care during COVID-19 were noted in 13 countries/regions surveyed, namely Belgium, Estonia, Ireland, Finland, France, Germany, Norway, Portugal, Switzerland, England, Wales, Scotland and Northern Ireland, six of which involved official policy amendments. These changes (displayed in table 1 and described in further detail in the following paragraphs) were largely considered temporary, and pertained mostly to the expansion of home-based medical abortion and modes of dispensing mifepristone (the first medication dispensed for medical abortion). None of the surveyed countries/regions expanded the legal gestational age limit for abortions (including the 16 countries/regions permitting elective abortions only up to 12 weeks or less) and none of the 12 surveyed countries/regions requiring mandatory waiting periods officially lifted this regulation, although abortion providers in Portugal have forgone this rule during the COVID-19 outbreak.

\section{Innovations to promote telemedicine and self-managed abortion solutions}

Most of the amendments were designed to minimise in-person clinical consultations. Six countries/regions officially expanded home medical abortion during the COVID-19 outbreak (England, Wales, Northern Ireland, Scotland, France and Finland), either as a new service delivery option or through expansion of the gestational age eligibility limit. In Switzerland, some providers also extended the gestational age limit for home medical abortion from 7 to 9 weeks, although this was not officially enacted. Medical abortion at home (including home use of both mifepristone and misoprostol) beyond 9weeks was only offered in four countries/regions (England, Wales, Scotland and Sweden), while misoprostol (taken 24-48 hours after mifepristone for medical abortion) could be administered at home up to 9 weeks and 6 days gestation in Belgium, Portugal and Northern Ireland and up to 10 weeks in Finland (where mifepristone was dispensed in a clinical setting).

Telemedicine for medical abortion, permitted in the Stockholm region of Sweden before COVID-19, was provided in five additional countries/regions during the pandemic including England, Wales, Scotland, France and Ireland. Other requirements for in-person consultations were partially alleviated by encouraging phone consultations in Belgium, Portugal and Estonia (although not officially enacted) or by telemedicine for post-abortion visits in Portugal. Other country-specific measures to reduce facility-based interactions involved support for non-use of ultrasound for gestational dating (gestation based on last menstrual period when certain) in early pregnancy in England, Wales, Scotland and France, and extending abortion privileges to community-based gynaecologists in Norway.

Regulations governing the dispensation of mifepristone were also reconsidered in five countries/regions (England, Wales, Scotland, France and Ireland). During the pandemic, pharmacy access to prescribed mifepristone was permitted in France, where it was not permitted before COVID-19, while the drugs could be delivered by mail in four countries/regions (England, Wales, Scotland and Georgia) or home-delivered in England, Wales, Scotland and Ireland.

\section{Rising inequities in access to abortion services during COVID-19}

Altogether the diversity of pre-COVID-19 rules regulating abortion coupled with inconsistent responses to the COVID-19 crisis has exacerbated a heterogeneous landscape of abortion provision in Europe, ranging from the most restrictive conditions denying elective abortions to more progressive solutions promoting telemedicine in England, Wales, Scotland, France, Ireland and Sweden. The summary of abortion regulations during COVID-19 (table 2) displays inequities in terms of gestational age limits and waiting periods, as well as required in-person consultations, access to surgical abortion, or delivery of medical abortion drugs.

Concerns over these rising inequities in access to abortion in Europe were voiced by a number of countryexperts, who acknowledged the impact of international border closures and restrictions on movement imposed by lockdowns on women's access to abortion care. They suggested that these constraints were aggravated by the escalating numbers of women who are victims of abuse ${ }^{812}$ and for women who have poor access to abortion services, due to their geographical or socioeconomic circumstances. One expert further noted that the absence of public action in the Netherlands to address these obstacles, including the inability to access abortion services for women who had little freedom of movement during COVID-19 restrictions (including victims of abuse), was challenged in court, but with limited success in lifting these unnecessary regulations.

\section{DISCUSSION}

This landscape of abortion access in COVID-19stricken Europe has revealed a general lack of government response to ensuring continuity of care for women in need of this essential service at the height of the pandemic. Responses ranged from political attempts to further proscribe abortion in Poland or prohibit access in Hungary, to progressive actions expanding telemedicine solutions amid transport limitations and medical service disruptions in England, Wales, Scotland, 
Table 1 Changes to abortion services (mostly related to medical abortion*) instituted in 10 European countries in the context of COVID-19

\begin{tabular}{|c|c|c|c|}
\hline Country & Changes & $\begin{array}{l}\text { Regulatory process and date of } \\
\text { implementation }\end{array}$ & $\begin{array}{l}\text { Assessment of changes: } \\
\text { permanent or temporary }\end{array}$ \\
\hline Belgium & $\begin{array}{l}\text { Changes in abortion care during COVID-19 depended on } \\
\text { facility type and region. } \\
\text { While outpatient abortion centres ( } 84 \% \text { of abortions } \\
\text { in Belgium) continued to provide regular abortion care, } \\
\text { some hospitals stopped offering abortion care or reduced } \\
\text { facility-based abortion by } \\
0 \text { promoting medical abortions up } \\
\text { to } 9 \text { weeks }+6 \text { days with home use of } \\
\text { misoprostol } \\
\text { o referring later abortions to outpatient } \\
\text { abortion centres, } \\
\text { French-speaking abortion centres promoted medical } \\
\text { abortion up to } 8 \text { weeks with misoprostol at home (with } \\
\text { phone supervision). } \\
\text { Flemish abortion centres provided the first consultation } \\
\text { online with a one-step visit for surgical abortion after } \\
\text { the mandatory } 6 \text {-day waiting period (nearly no medical } \\
\text { abortions). }\end{array}$ & $\begin{array}{l}\text { Recommendations were not endorsed by the } \\
\text { government's Department of Health but were } \\
\text { implemented by abortion centres in mid-March } \\
\text { (1 week after lockdown) }\end{array}$ & Unsure \\
\hline Estonia & $\begin{array}{l}\text { Fewer visits to clinic. } \\
\text { Remote consultation (usually by phone). } \\
\text { Use of misoprostol at home is encouraged (available } \\
\text { before COVID 19). }\end{array}$ & $\begin{array}{l}\text { Recommendations by Estonian Society of } \\
\text { Gynaecologists and Clinicians not officially } \\
\text { approved }\end{array}$ & $\begin{array}{l}\text { Some changes will be } \\
\text { permanent }\end{array}$ \\
\hline Finland & $\begin{array}{l}\text { Home use of misoprostol extended up to } 10 \\
\text { weeks }+0 \text { days (previously } 9 \text { weeks }+0 \text { days) in Helsinki. }\end{array}$ & Change in local practice & $\begin{array}{l}\text { Temporary but possibly to } \\
\text { become permanent }\end{array}$ \\
\hline France & $\begin{array}{l}\text { Gestational limit of medical abortion at home raised from } \\
7 \text { weeks to } 9 \text { weeks+0 days. } \\
\text { Medical abortions all performed by telemedicine without } \\
\text { mandatory in-person consultation. } \\
\text { Pharmacy access to mifepristone and misoprostol through } \\
\text { a medical order directly sent to the pharmacy by the } \\
\text { provider. }\end{array}$ & $\begin{array}{l}\text { Guidelines by National Society (CNGOF) } 26 \\
\text { March } 2020 \\
\text { Guidelines by National Health Agency } 10 \text { April } \\
2020 \\
\text { Law } 15 \text { April } 2020\end{array}$ & $\begin{array}{l}\text { Upper limit of } 9 \text { weeks } \\
\text { gestation may be permanent, } \\
\text { other measures temporary }\end{array}$ \\
\hline Germany & $\begin{array}{l}\text { Mandatory counselling can be performed via telemedicine, } \\
\text { but most abortions are performed surgically (very small } \\
\text { number of medical abortions). }\end{array}$ & $\begin{array}{l}\text { Ministry } \\
\text { No official guidelines for abortion }\end{array}$ & Unsure \\
\hline Hungary & $\begin{array}{l}\text { In the public sector, surgical abortions (only method } \\
\text { available in Hungary) were ceased, as a result of the } \\
\text { government ban on non-life-saving procedures. } \\
\text { With the closing of most of the private clinics during the } \\
\text { pandemic, abortion was unavailable in the private sector. }\end{array}$ & Officially, no change & Temporary \\
\hline Ireland & $\begin{array}{l}\text { Remote consultation with a medical practitioner for } \\
\text { medical abortion, with face-to-face consultations only in } \\
\text { exceptional circumstances. } \\
\text { Both mifepristone and misoprostol are taken at home up } \\
\text { to } 9 \text { weeks. } \\
\text { Informed consent may be obtained verbally or by } \\
\text { confirmatory email from the patient to the doctor. } \\
\text { The guidance states that arrangements must be made for } \\
\text { the collection of medical abortion medications. } \\
\text { The need to administer anti-D to a patient with a Rhesus- } \\
\text { negative blood group whose pregnancy is less than } 9 \\
\text { weeks' gestation was suspended. }\end{array}$ & $\begin{array}{l}\text { Revised Model of Care for Termination in Early } \\
\text { Pregnancy issued by the Health Service Executive } \\
\text { and Department of Health on } 7 \text { April } 2020\end{array}$ & Temporary \\
\hline Norway & $\begin{array}{l}\text { Introduction of non-facility-based abortion by allowing } \\
\text { gynaecologists outside of hospitals to conduct abortion } \\
\text { up to } 12 \text { weeks' gestation (pre-COVID, abortions were } \\
\text { only facility-based). }\end{array}$ & Decision by the Directorate of Health & Temporary \\
\hline Portugal & $\begin{array}{l}\text { Omit the waiting period. } \\
\text { Only one visit with a doctor for ultrasound and abortion. } \\
\text { Postponement of follow-up visit when possible or follow- } \\
\text { up visit by telemedicine. }\end{array}$ & $\begin{array}{l}\text { Recommendations by Portuguese Society of } \\
\text { Contraception and Clinicians not officially } \\
\text { approved but implemented by Obstetrician } \\
\text { Services }\end{array}$ & Temporary \\
\hline
\end{tabular}


Table 1 Continued

\begin{tabular}{|c|c|c|c|}
\hline Country & Changes & $\begin{array}{l}\text { Regulatory process and date of } \\
\text { implementation }\end{array}$ & $\begin{array}{l}\text { Assessment of changes: } \\
\text { permanent or temporary }\end{array}$ \\
\hline Switzerland & $\begin{array}{l}\text { Some clinics have extended the gestational age limit for } \\
\text { medical abortion from } 7 \text { to } 9 \text { weeks due to difficulties } \\
\text { accessing surgical abortion. }\end{array}$ & Recommendations were not officially approved & Unsure \\
\hline $\begin{array}{l}\text { UK (Wales and } \\
\text { England) }\end{array}$ & $\begin{array}{l}\text { Use of telemedicine and approval for home use of both } \\
\text { mifepristone and misoprostol up to } 9+6 \text { weeks as per } \\
\text { guidelines. } \\
\text { The new guidelines support non-use of ultrasound at this } \\
\text { gestation for example if LMP is certain and no significant } \\
\text { risk of ectopic pregnancy. } \\
\text { Approval for home use includes postal delivery of } \\
\text { medication. }\end{array}$ & $\begin{array}{l}\text { Department of Health of the Wales Government } \\
\text { on } 31 \text { March } 2020 \\
\text { Department of Health of the English Government } \\
\text { on } 30 \text { March } 2020\end{array}$ & Unsure \\
\hline UK (Scotland) & $\begin{array}{l}\text { Use of telemedicine and approval for home use of both } \\
\text { mifepristone and misoprostol up to } 11 \text { weeks+6 days } \\
\text { as per Scottish guidelines. The new guidelines support } \\
\text { non-use of ultrasound at this gestation, for example, in } \\
\text { the case LMP is certain and there is no significant risk of } \\
\text { ectopic pregnancy. } \\
\text { Approval for home use includes postal delivery of } \\
\text { medication. } \\
\text { The need to administer anti-D to a patient with a Rhesus- } \\
\text { negative blood group having medical abortion at 10-12 } \\
\text { weeks has been suspended. }\end{array}$ & $\begin{array}{l}\text { Department of Health of the Scottish Government } \\
\text { on } 30 \text { March } 2020\end{array}$ & Unsure \\
\hline $\begin{array}{l}\text { UK (Northern } \\
\text { Ireland) }\end{array}$ & $\begin{array}{l}\text { Abortion services started to operate in April } 2020 \text { for first- } \\
\text { trimester abortions. } \\
\text { Use of misoprostol at home currently up to } 10 \text { weeks. }\end{array}$ & $\begin{array}{l}\text { The provision of abortion services following } \\
\text { Northern Ireland's October } 2019 \text { legislation was } \\
\text { implemented by the Department of Health of the } \\
\text { Northern Ireland Government on } 9 \text { April } 2020\end{array}$ & Permanent \\
\hline
\end{tabular}

*In Europe, medical abortion is performed using mifepristone followed by misoprostol.

LMP, last menstrual period.

France and Ireland. As such, the COVID-19 pandemic has crystallised growing inequities in abortion access across the continent.

The closing of borders aggravated human rights violations denying women access to comprehensive SRH services, while also exposing the burden and health hazards related to outdated requirements imposing unnecessary facility-based visits. None of the surveyed countries considered expanding the gestational limit for abortions performed for non-medical reasons, with gestational ages ranging from 7 weeks in the Czech Republic to up to 24 weeks in England, Wales and Scotland. The mandatory waiting period was unofficially removed by providers in one country but remained in 15 others, further restricting access given limited transportation and reduced service availability. While mounting evidence supports home abortion and telemedicine solutions for medical abortion, shown to be safe, effective, and acceptable to women, ${ }^{13}$ only 21 countries/regions in Europe provided any home abortion solutions during COVID-19 (13 countries up to 9 weeks and eight countries/regions beyond 9 weeks). In some of these countries, only misoprostol could be taken at home (Estonia, Belgium, Denmark, Northern Ireland or Portugal, for example) while mifepristone was still required to be taken in a clinical facility. Only six countries/regions offered abortion by telemedicine.

The lack of political will to lift unnecessary regulations is discouraging, yet we recognise the concerted efforts of some governments and providers who swiftly acted to sustain abortion care during COVID-19 disruptions. This was accomplished by maintaining facility-based abortion care as an essential service and shifting to non-facility care through a constellation of innovative actions including phone consultations, telemedicine and new ways of delivering medications to women. Consequently, home abortion solutions were expanded in a number of countries/regions, and abortion by telemedicine was practised in six countries/regions. We suggest these innovations should serve as guiding examples to unify country policies towards ensuring continuity of abortion care during COVID-19 or other outbreaks in Europe. We believe that these advances, mostly conceived as temporary responses to a health crisis, could serve as catalyst towards 'liberalising' abortion provision and that they should become the standard of care.$^{13}$ Such an expansion, however, should carefully be grounded in evidence by updating current clinical guidelines to specify the recommendations for home medical abortion and telemedicine abortion provision. In addition, these remote care options should be included in public health plans to guarantee equity in abortion access. Such reforms are urgently needed as fewer than half of the countries in Europe provide full funding for abortion services ${ }^{14}$ and only a few have passed legislation to include telehealth expertise in their public health plans. 


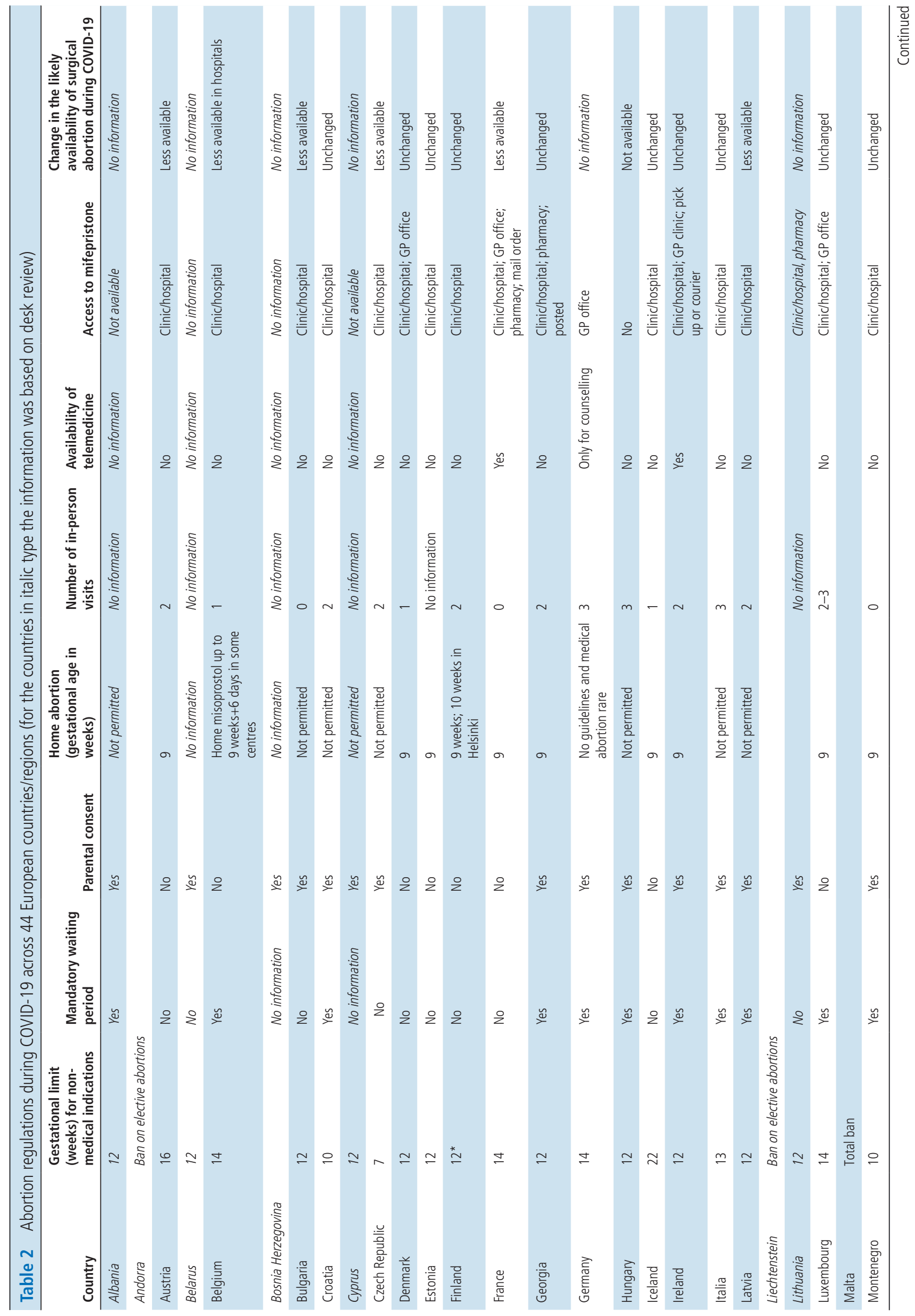




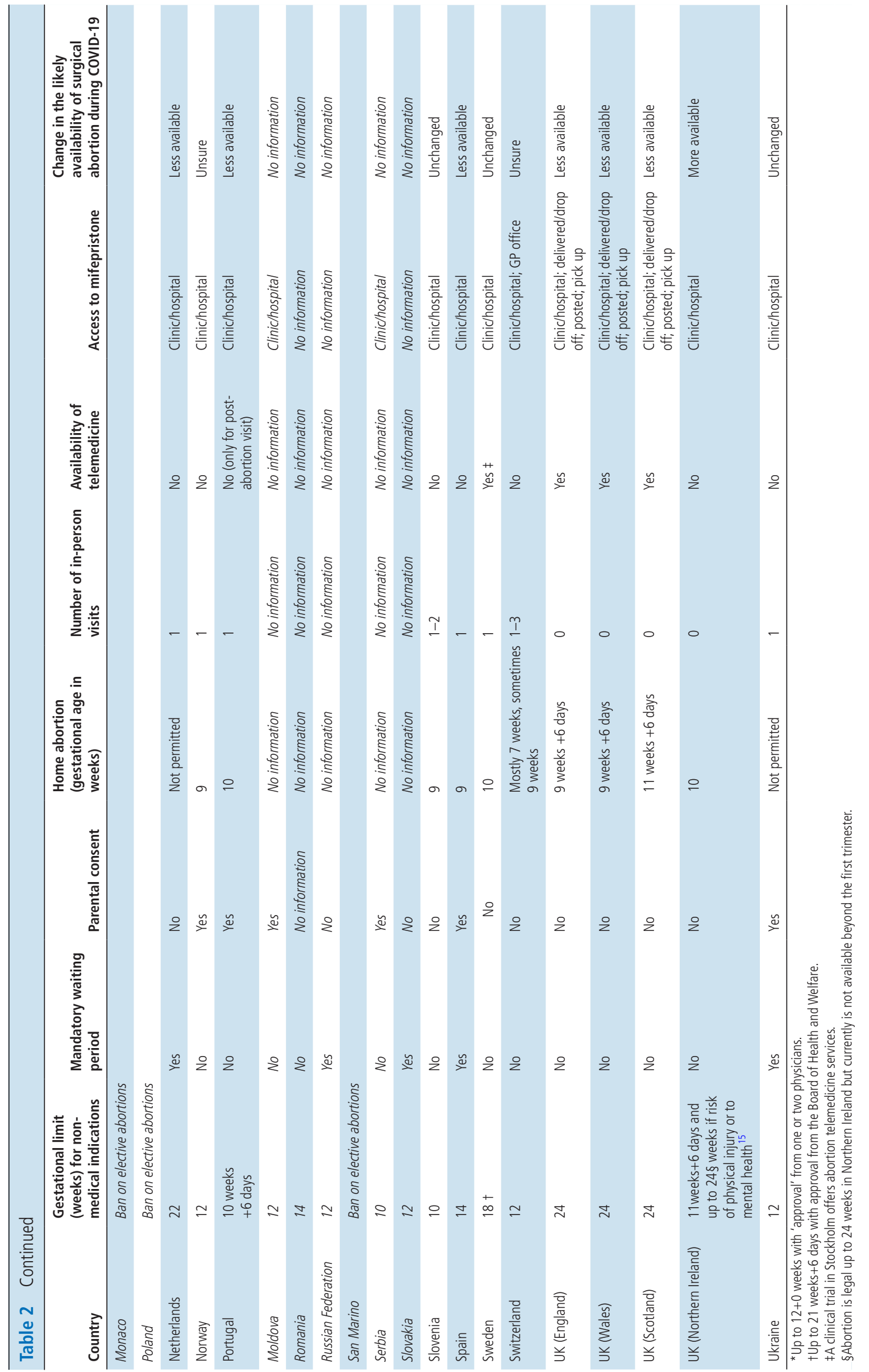

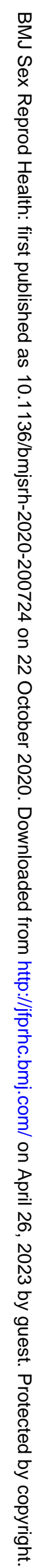




\section{CONCLUSIONS}

This study shows wide disparities in access to abortion care during COVID-19, with reduced access in a number of countries due to government inaction in lifting abortion regulations to enable safe abortion care amid healthcare system disruptions. Nonetheless, a few countries deployed innovative strategies during the outbreak, promoting telemedicine and self-management solutions. We stress the need for such innovations to guide a unified response to ensure continuity and equity of abortion care for women across the European continent during the COVID-19 pandemic and beyond.

Acknowledgements The authors thank the following expert informants: Dr Fiala (Austria), Dr Verougstraete (Belgium), Dr Cvetkoff (Bulgaria), Dr Stepanic (Croatia), Dr Lubusky (Czech Republic), Dr Karro (Estonia), Dr Heikinheimo (Finland), Dr Agostini (France), Dr Shengelia (Georgia), Dr Asatiani (Georgia), Dr Halder (Germany), Dr Jónsdóttir (Iceland), Dr Murphy (Ireland), M Taylor (Ireland), A Spillane (Ireland), Dr Henchion (Ireland), Dr Parachini (Italy), Dr Lazdane (Latvia), Dr Chery (Luxembourg), Dr Cassar (Malta), Dr Haliti (Montenegro), Dr Gomperts (Netherlands), Dr Løkeland-Stai (Norway), Dr Bombas (Portugal), Dr Pinter (Slovenia), Dr Lertxundi (Spain), Dr Gemzell-Danielsson (Sweden), Dr Choon-Kang (Switzerland), Dr Cameron (UK) and Dr Podolskyi (Ukraine). They also thank B Fredrick for her comments on this analysis.

Contributors CM, AG, SC and KG-D conceived the study. $\mathrm{CM}$ and MS developed the study instrument with input from AG, SC and KG-D. CM and MS led analyses of data submitted by country-experts along with desk review of country-level policies for which expert feedback was not received. CM led manuscript writing, with contributions from all the authors who also gave final approval for manuscript submission.

Funding The authors have not declared a specific grant for this research from any funding agency in the public, commercial or not-for-profit sectors.

Competing interests None declared.

Patient and public involvement Patients and/or the public were not involved in the design, or conduct, or reporting, or dissemination plans of this research.

Patient consent for publication Not required.

Provenance and peer review Not commissioned; externally peer reviewed.

Data availability statement All data relevant to the study are included in the article or uploaded as supplementary information. The data collected for this study are displayed in the tables.

Open access This is an open access article distributed in accordance with the Creative Commons Attribution Non Commercial (CC BY-NC 4.0) license, which permits others to distribute, remix, adapt, build upon this work noncommercially, and license their derivative works on different terms, provided the original work is properly cited, appropriate credit is given, any changes made indicated, and the use is non- commercial. See: http://creativecommons.org/licenses/by-nc/4. $0 /$.

\section{ORCID iDs}

Caroline Moreau http://orcid.org/0000-0002-8637-6249

Sharon Cameron http://orcid.org/0000-0002-1168-2276

\section{REFERENCES}

1 ESHRE Capri Workshop Group. Induced abortion. Hum Reprod 2017;32:1160-9.

2 Say L, Chou D, Gemmill A, et al. Global causes of maternal death: a WHO systematic analysis. Lancet Glob Health 2014;2:e323-33.

3 Singh S, Maddow-Zimet I. Facility-based treatment for medical complications resulting from unsafe pregnancy termination in the developing world, 2012: a review of evidence from 26 countries. BJOG 2016;123:1489-98.

4 Federal Statistical Office of Switzerland. Pregnancy terminations in Switzerland in 2018. Available: https:// www.bfs.admin.ch/bfs/fr/home/statistiques/sante/etat-sante/ reproductive/interruptions-grossesses.html [Accessed 18 May 2020].

5 National Board of Health and Welfare. Swedish Ministry of Health. Statistics on abortion in 2018. Available: https:// www.socialstyrelsen.se/globalassets/sharepoint-dokument/ artikelkatalog/statistik/2019-5-18.pdf [Accessed 18 May 2020].

6 Direction de la recherche, des études, de l'évaluation et des statistiques. French Ministry of Health. Induced abortion statistics 2018, France. Available: https://drees.solidarites-sante. gouv.fr/IMG/pdf/er1125.pdf [Accessed 18 May 2020].

7 Department of Health \& Social Care. Abortion statistics, England and Wales, 2018. Available: https://assets.publishing. service.gov.uk/government/uploads/system/uploads/ attachment_data/file/808556/Abortion_Statistics_England_ and_Wales_2018_1_.pdf [Accessed 18 May 2020].

8 Roesch E, Amin A, Gupta J, et al. Violence against women during covid-19 pandemic restrictions. BMJ 2020;369:m1712.

9 Hussein J. COVID-19: what implications for sexual and reproductive health and rights globally? Sex Reprod Health Matters 2020;28::1:1746065.

10 Todd-Gher J, Shah PK. Abortion in the context of COVID-19: a human rights imperative. Sex Reprod Health Matters 2020;28:1758394.

11 House of Commons. Abortion in Northern Ireland: recent changes to the legal framework. Number CBP 8909. Available: https://commonslibrary.parliament.uk/research-briefings/cbp8909/ [Accessed 26 Jun 2020].

12 Mahase E. Covid-19: EU states report 60\% rise in emergency calls about domestic violence. BMJ 2020:m1872.

13 Endler M, Lavelanet A, Cleeve A, et al. Telemedicine for medical abortion: a systematic review. BJOG 2019;126:1094102.

14 Grossman D, Grindlay K, Burns B. Public funding for abortion where broadly legal. Contraception 2016;94:453-60.

15 UK Government. A new legal framework for abortion services in Northern Ireland. Available: https://assets.publishing.service. gov.uk/government/uploads/system/uploads/attachment_data/ file/875380/FINAL_Government_response_-_Northern_ Ireland_abortion_framework.pdf 